\title{
CHRONOLOGICAL AGES AND THEIR IMPORTANCE TO LAW AND FORENSIC PRACTICE IN SRI LANKA
}

\author{
Induwara Gooneratne
}

\author{
Department of Forensic Medicine, University of Peradeniya, Sri Lanka
}

\begin{abstract}
Age of a person is an important parameter in forensic practice both in the living and in the dead. This paper attempts to identify different chronological ages that are relevant to forensic contexts in our domestic law. As per the Sri Lankan law, ages eight, twelve, sixteen, fourteen, eighteen and twenty one are critically important when there is a dispute about the age or information regarding the age of a person in these age categories are missing.
\end{abstract}

Key words: Chronological age, Age estimation, Age and law

Corresponding author:

induwarag@yahoo.com

\section{INTRODUCTION}

Age of a person is an important parameter in forensic practice both in the living and in the dead. Age of a person can be useful in identifying a person, incriminating a suspect and also for exonerating a suspect in a forensic/legal context. Providing an estimation of the age of a person is a common activity in forensic practice. This is more common where the identity of the person is not known especially in instances where the body is decomposed, burnt or fragmented. Certainly the age estimation of the living is also not uncommon in forensic contexts.

Despite the importance of age in forensic practice, many are unaware as to the law regarding which ages could be important in forensic contexts. Of course common instances like age limit for consent for sex is widely known but there are other laws that require the estimation of age in a forensic context which many seem to ignore. Therefore, this paper attempts to identify different chronological ages that are relevant to forensic contexts in our domestic law.

\section{Chronological Age and Biological Age}

Chronological age refers to the actual time in years and months a person has been alive. This means the truth of the person's age. While birth certificates and passports are good documentary evidence to establish one's chronological age, there have been many instances where these documents have been forged or altered. In other instances, these documents are lost, destroyed or not prepared due to many reasons. In criminal instances, when age is a mitigating factor or an incriminating factor some accused have reportedly destroyed their documentary evidence of chronological age.

Biological age in contrast is 'how old does he or she seem' taking into consideration his or her biological parameters. Certainly this is an estimate. What is estimated in a forensic context is the biological age. The actual age or the chronological age of the person is not known to the forensic practitioner and the age of the suspect/victim is estimated using different types of biological data from the particular victim/suspect.

Two very important assumptions are made here which many tend to ignore. First assumption made is that the biological age and chronological ages are exactly the same or nearly the same. The second assumption is 
that biologically age of a person can be scientifically estimated to a point estimate meaning that the age of a person could be given as a year month and date. The truth is far from this. In other words, the biological age that is estimated is merely a statistical estimate which means that there is a standard error, a confidence interval and a standard deviation. In other words it is not possible for the forensic practitioner to provide an exact date of birth for the individual, nor he/she can provide at least an year with one hundred percent accuracy. What can be done is to provide with a rough estimate giving a possible age range. However, the legal fraternity and police expect that the forensic practitioner provides a point estimate of the age of the individual. Of course, this has valid reasons. The law technically says if someone is above a certain age a certain action will or will not apply. For example, in order to decide on a statutory rape when the consent of the woman is not contested, the age of the women is very important - if the woman is above 16 years of age then, there is no statutory rape when consent of the woman has been legally valid. As a consequence, determining the age (when it is unknown) of the woman whether it is 16 or above is technically very important to the court. However, what must be understood by the legal fraternity is that the forensic practitioner provides the opinion based on biological development parameters of the person which may show similar signs between a range of ages.

\section{Age Determination - The Scientific Approach}

Generally when a person is referred for age estimation, a physical examination which includes records of external features, anthropometric data, signs of sexual maturation and any age related development disorder are recorded. Despite their subjectivity and vagueness, these parameters are still important primary information. Then generally a radiographic examination of bone maturation will be assessed and the left hand is routinely used if the suspect/victim is a young adult. Then most importantly the dental development and age related information in the mouth are recorded clinically as well as using radiological methods. Certainly, the history provided by the victim/suspect is also relevant but the practitioner always bases his/her opinion on the scientific evidence that is available. Evidently, psychological maturity of the person has also been used at many instances however its use in forensic contexts especially in determining the chronological age has been debated. In post mortem situations fusions of cranial sutures, fusions of other long bones, age changes in symphysis pubis, age changes in ribs, amino acid racemisations have been useful, in addition to the above clinical and radiological approaches.

\section{Limits of Scientific approach}

Physical characteristics of individuals can vary depending on many factors. For example nutritional factors, genetic factors, environmental factors can influence the growth and development of physical features of an individual. An equally significant aspect to consider is whether the individual is suffering from any condition that affects his/development which are known as developmental disorders.

Given the high reliability the law places on the opinion of the forensic practitioner on his/her age estimation report, it is relevant to mention that most of the time, the physical features or radiological characteristics are based on contrasting what is seen clinically or radiologically on the victim/suspect and what characteristics are already established through research that should be seen at certain age intervals. For example, clinically, if pubic hair is seen in the individual then the research has predicted the age of the individual (depending on the gender) a certain age range while there are established age ranges for the appearance and fusion of bones in wrist/hand.

Notwithstanding such wide usage of these approaches in estimating ages, we in Sri Lanka rely heavily on published western 
data. Noting the compelling evidence to suggest that there is significant variations of ages in these physical parameters depending on their genetic or ethnic origin, it is questionable as to how reliable would the estimate be for a Sri Lankan. If at all, there are only a few studies that are published using Sri Lankan participants - however they have their own scientific limits. For example, the sample sizes used in Sri Lankan samples have been minimal to extrapolate to a population while there are no reliable information for ethnic groups, socioeconomic groups, gender groups etc. On the other hand, as the age progresses from youth to adulthood, the reliability and availability of methods reduces. In this situation accuracy of determining the age of an individual becomes questionable.

\section{Ages and Sri Lankan Law}

Having discussed the above context, it is now important to explore and identify what ages are forensically important to consider in our legal system. The most important ages in forensic practice are those that are available in the penal code. In its section 75 ages eight is introduced as the minimum age of criminal liability while the ages between eight and twelve are introduced as doli incapax. This means that the ages eight, twelve and inbetween are criminally significant when the age is disputed or unavailable. Next important age under the penal code is the age of 16 which is introduced as age of consent for sex for females. This age which is very commonly contested is of very significance in forensic practice in Sri Lanka.

Next important age limit is the age of eighteen due to many reasons. The child rights policy of Sri Lanka recognizes a person below 18 years as a child. This age is critical in order to earn many privileges as a child to a person. Further, age of eighteen is considered the minimum age for legal marriage for both male and females in Sri Lanka under both general law and under Kandyan law. Age of 18 is important again for casting vote at elections, standing for elections, making a legal will, obtaining a driving licence and the like. Most importantly the age of majority in Sri Lanka is eighteen years according to Age of Majority Ordinance.

Moreover, age of twenty one is also important. For example, whether a person will be sent to prison or will be considered as a youthful offender depends on whether the person has reached the age of 21 . If the person has not reached 21 years but above sixteen years, he will not be sent to a prison for a criminal conviction but will be sent to a training school for youthful offenders. On the other hand, age 21 is further important in renouncing or applying for citizenship and at age 21 a person ceases receiving maintenance entitlements. Age of 14 becomes important for several reasons. It is the age up to which a child can be adopted, the age for employment in certain industrial settings.

\section{CONCLUSIONS}

While estimating age in forensic contexts appears an important endeavour, there are many challenges a forensic practitioner has to overcome in order to predict the best unbiased estimate. Owing to lack of research with adequate samples, most bone and teeth data available are invalidated for local populations. It is questionable as to the accuracy of using European or data from other populations to estimate ages of local populations in Sri Lanka given the research findings of variables that significantly affects biological age.

As per the law, ages eight, twelve, sixteen, fourteen, eighteen and twenty one are critically important when there is a dispute about the age or information regarding the age of a person in these age categories are missing. 


\section{REFERENCES}

1. Black S, Aggraval S .Age Estimation of the Living. Wiley Blackwell London.

2. Stavrianos C mastagus D Stavrianou I(2008) Dental Age Estimation of Adults. Research Journal of Medical Sciences 2(5)

3. Penal Code of Sri Lanka 2 of 1883 and 22 of 1995 ( Amendment)
4. Age of Majority Act 17 of 1989

5. Marriage Registration (Amendment) Act 18 of 1995

6. Legislative Enactments of Sri Lanka 